\title{
Commission 9
}

\section{Instruments and Techniques (Instruments et Techniques)}

\author{
President: J.C.Bhattacharyya \\ Vice-President: G.Lelievre
}

This report contains summaries of the business and scientific sessions held by Commission 9 and its Working Groups during the 22nd IAU General Assembly at Den Haag between August 15 and August 27, 1994. As part of the General Assembly program, Commission 9 also co-sponsored a Joint Discussion Meeting (J.D. 6: Sun and Heliosphere - Challenges for Solar Terrestrial Physics, Magneto-and Hydrodynamics) and one Working Group Meeting (WGM 2: Near-Earth Objects Detection) and members participated in the meetings. A special review meeting on Antarctic Astronomy was also attended by some commission members who participated in the discussions. The report will presumably be covered by Commission 34 .

The pre- and post-assembly symposia series covered two important topics in Instrumentation and Techniques. They are: Sub-milliarc-second optical astrometry in Symposium 166, and New developments in Array Technology and Applications in Symposium 167. Both were co-sponsored by Commission 9 and many members participated in the accompanying discussions. Full details will be published elsewhere in due course, and are not given in this report.

\section{Business}

\section{Business Meeting: 18 August 1994 Chair: J.C.Bhattacharyya}

The business session opened with a short introduction by Bhattacharyya, who briefly reviewed the activities of the Commission over the last three years. Although the Commission Newsletter started by the previous committee was continued, he felt more efforts need be spent in bringing it out more regularly. He expressed thanks to all members who have contributed to this storehouse of information about latest developments.

M.Cullum, Chairman of the WG on "Detectors" briefly reviewed the developments in the field of detectors; no separate meeting of the Working Group on "Detectors" were held. He covered the developments in the large format CCD arrays, including the increased popularity of foundry runs, inprovements in thinning techniques and back surface treatments. Largest chips that are in common astronomical use are $2048 \times 2048$ arrays of 15 micron square pixels; larger chips of $4096 \times 4096$ of 7.5 or 15 micron pixels have been tested in laboratories; this size perhaps represents the largest that can be accommodated within the 4 inch wafers used by many manufacturers. Efforts to achieve even larger formats have mainly concentrated on making mosaics of chips that are designed to be buttable with a 
gap of less than $0.5 \mathrm{~mm}$ between the butted sides.

In his brief review, Cullum also mentioned efforts to improve sensitivities, spectral responses and readout techniques. Rapid development in the Infra-red detectors were also touched upon.

W.J.Tango, Chairman of the WG on "HARI" also briefly spoke about the activities of his Working Group. A separate session discussing plans and developments in the field was held on 22 August 1994. A report about this meeting is included in the next section.

R.M.West, Chairman of the Working Group on "Wide Field Imaging" presented a glimpse of activities, developments and problems in this field. A separate session for discussion of these points was held on 23 August 1994 a report of which is given in the next section.

The Commission decided on continuing all the three Working Groups for one more term. As per the suggestions of the outgoing Chairmen, the following were elected to Chair the three Working Groups for the next three years:

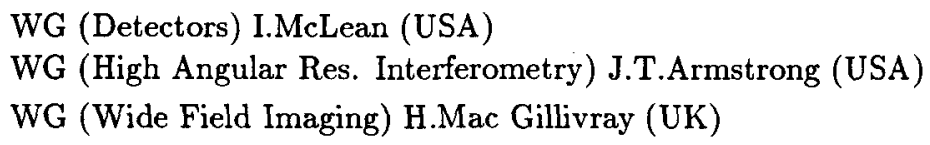

Some further details of the Working Committees are given in the next section.

The meeting next discussed the proposed reorganisation of the IAU Commissions. All the members present were invited to express their opinions. It was generally felt that the proposals are welcome in the interest of improvements in functioning of the IAU, but they need careful examination before any regrouping is done. The IAU Executive Committee had a meeting of Commission Presidents on 15 August 1994 and a second one was scheduled for 22 August 1994 for the same purpose, the Commission agreed to abide by the decision of the Executive Council.

The meeting then elected the new Organizing Committee for Commission 9 for the next three years. Dr G.Lelievre was elected as the new President and David Malin, the next Vice-President. The composition of the organizing committee will be as follows:

$\begin{array}{lll}\text { President } & \text { G.Lelievre } & \text { France } \\ \text { Vice-President } & \text { D.F.Malin } & \text { Australia } \\ \text { Members } & \text { M.Cullum } & \text { Germany } \\ & \text { F.Merkle } & \text { Germany } \\ & \text { I.McLean } & \text { USA } \\ \text { Su Ding Qiang } & \text { China } \\ & \text { W.Tango } & \text { Australia } \\ & \text { R.M.West } & \text { Germany } \\ & \text { J.M. Mariotti } & \text { France }\end{array}$


Two Chairmen of the WG viz Dr J.T.Armstrong and Dr MacGillivray will also be O.C. members (The third WG Chairman Dr I.McLean is already in the O.C.). It was proposed during the meeting that in case Dr Merkle declines the membership, Dr Hans Beck (Germany) may be included in his place.

It was also decided that Prof. J.C.Bhattacharyya, the retiring President will continue as a member of the Organizing Committee for one term.

The meeting concluded with thanks to all members present by the Chair.

\section{Working Group Meetings}

\section{Wide Field Imaging (Chairman, R.West)}

The WG met during a $90-\mathrm{min}$ session on 23 August 1994 at the time of the 22nd IAU General Assembly in The Hague. The Chairperson (R. West) gave a brief overview of the activities since the WG was created in 1991. A "membership" list had been established with about 200 individuals in about 36 countries; the work of the WG had mostly concentrated on five sub-sections: Sky Surveys and Patrols, Photographic Techniques, WideField CCD Techniques, Digitisation Techniques, and Archieval/Retrieval (of large data sets). Main activities included the publication of six Newsletters (Editor: H.MacGillivray), three meetings of the Organising Committee (OC), the organisation of IAU Symposium 161 (Astronomy from Wide-Field Imaging; Proceedings published in July 1994) as well as the establishment of a Wide-Field Plate Data Archive with nearly 2 million entries (in Sofia; responsible: M.Tsvetkov). B.Lasker reported about very successful meetings on related matters in Bandung (Schmidt telescopes) and Minneapolis (Digitised Sky Surveys) in 1994. The subjects discussed included the future use of Schmidt telescopes, in particular the implementation of CCD's, as well as faster and more exhaustive registration of information on large photographic plates. M.Tsvetkov reported on the progress on the Plate Data Archive in Sofia which now has comprehensive files for more than 500,000 widefield ( $>1$ degree) photographic plates. The possibility of including also solar plates and parallax plates was welcomed. B.Lasker then discussed some of the current projects for digitised sky surveys that will soon lead to deep exposures of the entire sky being available in computer-readable form.

R.West informed that Commission 9, in its preceding meeting, had agreed to the continuation of the WG for the next triennium (1994-1997) and also to the composition of the new OC: H.MacGillivray (UK, Chair), H.Lorenz (Germany, Secretary), J.-S. Chen (China, Nanking), V. de Lapparent (France), G.Djorgovsky (USA), B.Lasker (USA), D.Malin (Australia), A.Maury (France), S.Okamura (Japan), M.Tsvetkov (Bulgaria). The possibility of incorporating the WG on the "Space Schmidt" (Commission 28) was welcomed by Commission 9, but had apparently not yet been decided.

During the ensuing discussion, E.Griffin raised the question about the future of 
the Sonneberg Observatory, already the subject of various resolutions by IAU bodies. The present prospects were rather bleak and it was not felt that much could be done, although it seemed that the plate archive would now be moved to the Tautenburg Observatory. The possibility of future meetings of the WG was discussed and it was agreed that it would be desirable to have at least one meeting, possibly a workshop on a more restricted topic in 1995 or 1996, before the next meeting at the time of the 1997 IAU General Assembly. There were several suggestion for the site of such a meeting: North America, Bulgaria and/or Greece were mentioned.

\section{High Angular Resolution Interferometer (Chairman, W.J.Tango)}

The Working Group met on 22 August 1994 at the 22nd General Assembly. In discussing the future activities of the group, it was agreed that a main goal should be the development of an awareness on the wider astronomical community of the impact that high angular resolution observations will have on astronomy.

Dr J.Thomas Armstrong was elected new Chair by acclamation.

The following were elected by acclamation to the new Organizing Committee:

$\begin{array}{ll}\text { J.E.Baldwin } & \text { UK } \\ \text { A.M.Cherepashchok } & \text { Russia } \\ \text { O.v.d. Lühe } & \text { (ESO) } \\ \text { A.Labeyrie } & \text { France } \\ \text { W.McAlister } & \text { USA } \\ \text { W.J.Tango } & \text { Australia (past Chair) } \\ \text { C.W.Townes } & \text { USA }\end{array}$

Following the meeting, the OC met and proposed a colloquium to be held in 1996 .

Appendix-I

\section{Proposed colloquium on Scientific Advances Made by Long-Baseline Optical and Infrared Interferometers.}

The Organizing Committee of the Working Group on High Angular Resolution Interferometry has met and recommends the following resolution:

Several long-baseline optical and infrared interferometers are now taking data, including GI2T, ISI, COAST, SUSI, and IOTA; and two others, NPOI and ASEPS-0, will soon be operational. The Working Group on High Angular Resolution Interferometry proposes a Colloquium in the (northern) autumn of 1996 to discuss the scientific advances made by these instruments. Topics to be discussed may include stellar diameters, binary star orbits, stellar atmospheres and surface activity, circumstellar dust and gas, wide- and narrow-angle astrometry, and searches for brown dwarfs and extra-solar planets, as well as technical aspects of optical and infrared long-baseline interferometry. 
Possible members of the Scientific Organizing Committee include John Baldwin (UK), Charles Townes (USA), John Davis (Australia), Kenneth Johnston (USA), Antoine Labeyrie (France), Laurent Koechlin (France), Oskar van der Lühe (Germany), Wesley Traub (USA), Harold McAlister (USA), Sri Kulkarni (USA) and Robert E.Wilson (USA).

The US Naval Observatory (Washington, DC) has indicated that it would be willing to host such a meeting.

The contact person for this meeting is J.Thomas Armstrong, the new Chair of the Working Group:

J.Thomas Armstrong

(001) 202 653-0948 (Voice) US Naval Observatory (001) $202653-0941$ (Fax)

Astrometry Division AD-5

3450 Massachusetts Ave. NW

Washington, DC 20393-5420, USA

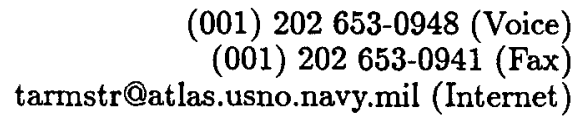

\section{A Special Meeting on Reorganization}

An informal meeting of the Presidents of Commission 9, 25 and 30 was held on 24 August 1994 at the Hague during the 22nd General Assembly. Following the decision of the IAU Executive Council to form a new division comprising Commissions 9, 25 and 30, the meeting was meant for mutually understanding the reactions of the members concerned. The following attended the meeting:

J.C.Bhattacharyya President, Commission 9

A.T.Young President, Commission 25

C.D.Scarfe President, Commission 30

G.Lelievre President elect Commission 9

It was agreed that the three Commissions should keep close contact with each other, and try to bring out periodic newsletters. Dr C.D.Scarfe, the retiring President of Commission 30 was nominated to take the leading part of the new Division's activities. 